\title{
28 Research Square \\ Translation and Psychometric Properties of the "Palliative Care Attitudes Scale (PCAS-9)"
}

Sajad Bagheri

Islamic Azad University

Maasoumeh Barkhordari-Sharifabad ( $\nabla$ barkhordary.m@gmail.com )

Islamic Azad University

Khadijeh Nasiriani

Shahid Sadoughi University of Medical Sciences

Mostafa Javadi-Estahbanati

Shahid Sadoughi University of Medical Sciences

\section{Research Article}

Keywords: Psychometric properties, attitude, palliative care, questionnaire, Persian

Posted Date: February 16th, 2022

DOI: https://doi.org/10.21203/rs.3.rs-1349384/v1

License: (9) This work is licensed under a Creative Commons Attribution 4.0 International License.

Read Full License 


\section{Abstract}

Background: Palliative care improves the quality of life of patients and their families; attitudes toward such cares are effective in accepting or rejecting them. It is necessary to assess the attitude of patients in this field. This study was aimed to translate and investigate psychometric properties of the Palliative Care Attitudes Scale (PCAS-9) in the Iranian community.

Materials \& Methods: This methodological research has been done in two parts of translation and psychometric evaluation. After translation and cultural adaptation, face validity (10 patients), content validity (10 experts), and construct validity were assessed using exploratory factor analysis (300 patients) and confirmatory factor analysis (210 patients). Then, internal consistency reliability and stability (30 patients) were measured for reliability. SPSS20 and LISREL were used for data analysis.

Results: PCAS-9 includes 9 items whose Persian translation were approved. Face and content validities were acceptable. Results of exploratory factor analysis showed three factors: emotional, cognitive, and behavioral. In confirmatory factor analysis, the values of fitness indices confirmed the appropriate fit of the model. The internal consistency reliability in the whole instrument was 0.929 and the intra-class correlation coefficient was 0.854 .

Conclusions: Findings showed that the Persian version of the PCAS-9 had acceptable psychometric properties. It can be used to evaluate patients' attitudes toward palliative care in the Iranian community.

\section{Background}

In the last decade, the image of health has changed in terms of disease and death, and infectious and contagious diseases have been replaced by chronic diseases [1]. The prevalence of several chronic diseases at the same time is increasing [2]. Chronic diseases are an important part of deaths between the ages of 20-64 years, covering a period of economic efficiency in life, and such cases are on the rise worldwide [3]. Most chronic diseases, by limiting a person's ability to live, can lead to deteriorating patients' general health, limited function, reduced quality of life, and increased health care costs [4].

The World Health Organization (WHO) has identified palliative care as a way to improve the quality of life of patients with incurable diseases as well as their families; palliative care begins with the diagnosis and continues throughout the course of the disease [5]. Many illnesses in the care process require the use of palliative care. These diseases include heart disease, cancer, chronic lung disease, AIDS, kidney failure, and multiple sclerosis [6]. Studies have shown that for many patients with advanced cancer, early initiation of palliative care improves the quality of life and patient survival [7]. The results also indicate that receiving previous palliative care is associated with greater satisfaction of patients' families with care [8]. In addition, palliative care reduces emergency room visits and care costs [9].

The use of palliative care is relatively low among advanced diseases, although its use has increased over the past twenty years [10-12]. However, inequality persists among those receiving palliative care [13]. 
Examining the patient's barriers to accessing palliative care helps to understand why patients receive less of this care [14]. Patients may equate palliative care with end-of-life care due to a lack of knowledge and a negative attitude toward palliative care [15].

One of the predictors of people's behavior is their attitude [16]. Attitude has a great impact on behavior, and if a person has a negative attitude towards a particular subject, one should not expect positive and supportive behaviors [17]. Studies have shown that perceived knowledge, attitudes, and threats are important predictors of health behaviors [18]. Attitudes toward behaviors may be strongly influenced by people's beliefs about those behaviors [19].

Appropriate tools are essential for measuring attitude. In this regard, the most appropriate tool is a tool that includes various dimensions of attitude [20]. The Palliative Care Attitudes Tool (PCAS-9) is a selfreport scale designed in 2020 by Perry et al. at Tulane University in the United States to assess palliative care attitudes for people with cancer and serious illness. The PCAS- 9 is comprised of three subscales that assess patients' fear of palliative care (emotional subscale), perceptions of its benefits (cognitive subscale), and willingness to utilize a referral (behavioral subscale). Patients answer items based on the Likert scale. Higher scores indicate more positive attitudes toward palliative care [21].

Iran's health system is facing an increasing number of chronic patients [22]. However, despite the high prevalence of chronic and incurable diseases in Iran, and importance of the palliative care attitudes, there is no reliable tool in this field in Persian. Therefore, the aim of this study was to translate the PCAS-9 into the Persian language and to investigate psychometric properties of this instrument in Iranian patients.

\section{Methodology}

The present study was a methodological study which was conducted in two stages. The first stage was the translation and cultural adaptation of the English version of the PCAS-9. The second stage of validation (face validity, content validity, construct validity, and reliability) dealt with the Persian version of PCAS-9. The samples in the translation stage were two fluent translators in Persian and English for forward translation and two translators for backward translation. In the psychometric phase, the study samples were 10 patients in need of palliative care were selected for face validation, 10 specialists in palliative care and psychometrics for content validation, 510 patients admitted to different wards of hospitals affiliated to Shahid Sadoughi University of Medical Sciences in Yazd/Iran for assessing the construct validity, and 30 patients for evaluating the reliability. Criteria for entering construct validity were having literacy, willingness to participate in the study, having a chronic illness requiring palliative care; exclusion criteria included having psychological problems such as communication and perceptual disorders and unwillingness to participate in the study.

\section{Translation and Cultural Adaptation}

At first, the instrument was translated and culturally adapted. After obtaining permission from the designer of the PCAS-9, Laura Perry, the translation was performed based on the approach proposed by 
Polit and Yang [23]. Two experienced translators fluent in English with native Persian language first translated the questionnaire into Persian. Then, the expert committee compared and combined both versions. The final translation of the PCAS-9 was translated back into English by two different translators. A final reconciliation was done with a committee of experts and the original designer.

\section{Psychometric Analysis}

In the next step, face validity (qualitative), content validity (qualitative) and construct validity were examined [24]. The translated instrument was distributed among 10 randomly selected patients to express their opinions on the difficulty and ambiguity about each item (qualitative face validity). In order to assess the content validity, 10 experts in the fields of palliative care and development of instruments were asked to present their corrective opinions in terms of grammar, use of appropriate words, and placement of items in their proper place in detail and in writing [25]. After carefully studying their views, appropriate corrections were made by the present research group. The comments were assessed and 9 items was revised.

The construct validity phase was performed by exploratory and confirmatory factor analysis on a sample size of 510 people. For large-scale studies, the sample size should have 10-20 participants per instrument phrase. In other words, for large-scale studies, the sample size should be between 100 and 250 people [26]. Thus, 300 patients were randomly selected for the exploratory factor analysis (EFA). The fit of the samples was evaluated using the Kaiser-Meyer-Olkin (KMO) index, which was equal to 0.805 . The $\mathrm{KMO}$ rate varies from 0 to 1 . The higher the rate, the more appropriate the factor analysis. Values above 0.9 are excellent and 0.8 are good $[27,28]$. Then, Bartlett's test was performed which was significant with chi-square $\left(\chi^{2}\right) 1295.04(P<0.001)$. Therefore, the samples had the necessary appropriateness and minimum requirements for performing EFA, and there was sufficient correlation between items to perform factor analysis. In EFA, the principal components method has been used to extract the factors and the Varimax method with Kaiser normalization has been used for factor rotation. Thus, if the value of the extracted share of each item is less than 0.5 , we exclude that item from factor analysis. Also, the criterion for deciding on the classification of items is special values higher than 1 and factor scores higher than 0.4 [29].

In the next step, the final number of factors was confirmed using CFA. In so doing, 210 participants were examined in confirmatory factor analysis (CFA). To judge the fit of the model, from indices of $\chi^{2} /$ degree of freedom (df), Goodness of Fit Index (GFI), Adjusted Goodness of Fit Index (AGFI), Root Mean square Residual (RMR), Normed Fit Index (NFI), Non-Normed Fit Index (NNFI), Incremental Fit Index (IFI), Comparative Fit Index (CFI) and Root Mean Square Error of Approximation (RMSEA) were used [30].

\section{Reliability}

In the present study, reliability was investigated using internal consistency and stability. The instrument was completed by 30 patients and re-completed at 2-week intervals. The most acceptable statistical test 
to calculate the reliability of stability is the intra-class coefficient correlation (ICC) [31]. If this index is higher than 0.7 , the stability rate is desirable [32].

Internal consistency is the most widely used method of assessing reliability. This type of reliability is used to test the correlation of different items in the tool. The most common method for determining internal consistency is the Cronbach's alpha coefficient. The optimal Cronbach's alpha coefficient is between 0 and 1, wherein a high score indicates a higher internal consistency. For interpretation, alpha coefficient values above 0.75 are considered acceptable [33].

Data collection was performed during July-November 2021. Data were analyzed using SPSS 20 and LISERL8.5.

\section{Results}

In the present study, $100 \%$ of the samples answered the items. The demographic variables of the study participants are presented in Table 1. The results showed that the total mean age of patients in need of palliative care was $15.45 \pm 78.52$ years with an age range of 18 to 85 years. Among the subjects $(\mathrm{N}=500)$, 293 (93.57\%) were male, 472 (5.92\%) were married, 294 (6.57\%) had postgraduate education, and 178 (34.9\%) had cardiovascular disease.

Table 1: Demographic characteristics of the respondents 


\begin{tabular}{|c|c|c|c|c|}
\hline \multirow[t]{2}{*}{ Variable } & \multirow[t]{2}{*}{ Levels } & $\begin{array}{l}\text { Total } \\
(\mathrm{N}=510)\end{array}$ & $\begin{array}{l}\text { EFA } \\
(N=300)\end{array}$ & $\begin{array}{l}\text { CFA } \\
(N=210)\end{array}$ \\
\hline & & Number (\%) & Number (\%) & Number (\%) \\
\hline \multirow[t]{2}{*}{ Gender } & Male & $293(57 / 93)$ & $178(59 / 3)$ & $115(54 / 8)$ \\
\hline & Female & $217(42 / 5)$ & $122(40 / 7)$ & $95(45 / 2)$ \\
\hline \multirow[t]{2}{*}{ Marital status } & Single & $38(7 / 5)$ & $24(8 / 0)$ & $14(6 / 7)$ \\
\hline & Married & $472(92 / 5)$ & $276(92 / 0)$ & 196(93/3) \\
\hline \multirow[t]{5}{*}{ Level of Education } & High school & $294(57 / 6)$ & $181(60 / 3)$ & $113(53 / 8)$ \\
\hline & Diploma & $134(26 / 3)$ & $76(25 / 3)$ & $58(27 / 6)$ \\
\hline & Bachelor & $56(11)$ & $32(10 / 7)$ & $24(11 / 4)$ \\
\hline & Master & $17(3 / 3)$ & $7(2 / 3)$ & $10(4 / 8)$ \\
\hline & Ph.D. & $9(1 / 8)$ & $4(1 / 3)$ & $5(2 / 4)$ \\
\hline \multirow[t]{6}{*}{ Type of disease } & Cardiovascular & 178(34/9) & 107(35/7) & $71(33 / 8)$ \\
\hline & Neurological & $35(6 / 9)$ & $17(5 / 7)$ & $18(8 / 6)$ \\
\hline & Kidney failure & $89(17 / 5)$ & $49(16 / 3)$ & $40(19)$ \\
\hline & Diabetes & $71(13 / 9)$ & $45(15)$ & $26(12 / 4)$ \\
\hline & Cancer & $121(23 / 7)$ & $73(24 / 3)$ & $48(22 / 9)$ \\
\hline & Respiratory & $16(3 / 1)$ & $9(3)$ & $7(3 / 3)$ \\
\hline \multicolumn{2}{|l|}{ Variables } & Mean (SD) & Mean (SD) & Mean (SD) \\
\hline \multicolumn{2}{|c|}{ Duration of the disease } & $51 / 88(58 / 72)$ & $53(58 / 56)$ & $50 / 28(59 / 04)$ \\
\hline \multicolumn{2}{|l|}{ Age } & $52 / 78(15 / 45)$ & $52 / 76(15 / 72)$ & $52 / 80(15 / 10)$ \\
\hline
\end{tabular}

\section{Face and Content Validity}

Based on the results of face validity, all items in the PCAS-9 were suitable in terms of the level of difficulty, appropriateness, and ambiguity. In the review of content validity, according to experts, corrective changes were applied in 9 items of the scale.

\section{Construct Validity}

Exploratory factor analysis was used for establishing construct validity. Based on the specific value above 1 and the Gravel diagram (Figure 1), palliative care attitudes, three factors, i.e., emotional, cognitive 
and behavioral, were extracted.

According to Table 2, three factors with a specific value higher than 1 have been extracted and all items related to this variable are included in these three factors. Also, according to the factor loads of the items, each of the items had the most variance in the same factor that was predetermined. Hence, each item measured exactly the factor for which it was designed; thus, the questionnaire items had the necessary validity. The extracted index value for all items was greater than 0.5 and no items were removed from the questionnaire (Table 2).

Table 2: Rotation factor matrix with principal component analysis method and varimax rotation method with Kaiser Normalization Palliative care attitudes scale questions:

\begin{tabular}{|c|c|c|c|c|}
\hline \multirow[t]{2}{*}{ Questions } & \multicolumn{3}{|c|}{ Component } & \multirow[t]{2}{*}{ Subscription } \\
\hline & 1 & 2 & 3 & \\
\hline Overall how much you will get stressed? & .764 & .085 & -.134 & 609 \\
\hline $\begin{array}{l}\text { How stressful is it to talk about physical symptoms or } \\
\text { complications such as pain, severe nausea, and difficulty } \\
\text { swallowing? }\end{array}$ & .856 & .017 & .006 & .733 \\
\hline $\begin{array}{l}\text { How stressful is it to talk about emotions, such as sadness, } \\
\text { fear, and anger? }\end{array}$ & .836 & -.028 & .046 & .701 \\
\hline $\begin{array}{l}\text { Do you think palliative care visits help improve your quality } \\
\text { of physical life? }\end{array}$ & -.042 & .743 & .345 & .672 \\
\hline $\begin{array}{l}\text { Do you think these visits will help relieve feelings of sadness } \\
\text { and depression? }\end{array}$ & .070 & .808 & .274 & .733 \\
\hline Do you think palliative care visits help prolong life? & .682 & .054 & .801 & .194 \\
\hline Would you want to have a palliative care visit? & -.015 & .346 & .876 & .888 \\
\hline $\begin{array}{l}\text { Would you try to make an appointment to visit as soon as } \\
\text { possible? }\end{array}$ & -.021 & .252 & .897 & .868 \\
\hline $\begin{array}{l}\text { If you were asked, would you visit once a month for a period } \\
\text { of several months? }\end{array}$ & -.067 & .274 & .859 & .817 \\
\hline
\end{tabular}

Then, the EFA result was tested using CFA. All indices confirmed the appropriate fit of the model (Table 3). Suitability test in confirmatory and path analyses showed RMSEA index, or Root Mean Square Error of Approximation of less than $8 \%, \chi^{2} / d f$ index less than 3 , and GFH, CFL, IFI, \& NNFI indices more than 90. The value (T-value) of the coefficients of the significance of each variable was greater than 2 and less than -2; consequently, the model has a good fit or in other words, has a reasonable approximation of the community [30]. Table 3 shows the model fit indices where all indicators confirmed the model. 
Table 3: The values of model fit indices and the result of fitting the Palliative Care Attitudes scale

\begin{tabular}{|lll|}
\hline Fit index & Optimal amount & Pattern value \\
\hline$\chi^{2} / d f$ & $3.00<$ & 0.84 \\
\hline GFI & $0.90>$ & 0.99 \\
\hline AGFI & $0.90>$ & 0.95 \\
\hline RMR & $0.05<$ & 0.020 \\
\hline NFI & $0.90>$ & 0.92 \\
\hline NNFI & $0.90>$ & 0.95 \\
\hline IFI & $0.90>$ & 0.97 \\
\hline CFI & $0.90>$ & 0.96 \\
\hline RMSEA & $0.08<$ & 0.000 \\
\hline
\end{tabular}

Figure 2 shows the dimensions of patients' attitudes toward palliative care in a standard and meaningful manner. As it shows, the membership of all the examined factors in this variable has been confirmed.

To determine the reliability, the internal consistency method and intra-class correlation coefficient (ICC) were used. The ICC value of patients' attitude to palliative care resulting from test-retest with two weeks interval and $95 \%$ confidence interval for the questionnaire factors were obtained as follows: emotional (ICC=0.841), cognitive (ICC=0.730), and behavioral $(I C C=0.935)$, respectively, . Therefore, this suggests the acceptability and appropriateness of reliability in time or repetition of the tool. Cronbach's alpha of all subscales and the whole test was more than 0.7 , which indicates a good internal correlation among each of the subscales and the whole instrument (Table 4).

Table 4: Reliability Indices of the Palliative Care Attitudes Scale (PCAS-9)

\begin{tabular}{|lllll|}
\hline Factor & Number of items & Cronbach's alpha & $\mathrm{Cl}(95 \%)$ & ICC \\
\hline Emotional & 3 & 0.935 & $0.708-0.919$ & 0.841 \\
\hline Cognitive & 3 & 0.892 & $0.505-0.862$ & 0.730 \\
\hline Behavioral & 3 & 0.971 & $0.881-0.967$ & 0.935 \\
\hline Total & 3 & 0.929 & $0.761-0.921$ & 0.854 \\
\hline
\end{tabular}

\section{Discussion}


The purpose of this study was to translate and evaluate the psychometric properties of the Palliative Care Attitudes Scale (PCAS-9). The psychometric evaluation makes it possible to prove validity and reliability, as it corrects most scales [26]. In this study, translation and psychometrics of the "Palliative Care Attitudes Scale (PCAS-9)" were studied among people with Persian language who were in need of palliative care.

The findings showed that the translation of the Palliative Care Attitudes Scale (PCAS-9) was acceptable. Due to the fact that this tool was designed in 2020, it was not possible to compare and discuss the translation of the tool in other languages. The results showed that the patients did not have any difficulty in understanding the items and the professors expressed their opinions about the items as well as the observance of grammar, appropriate diction, and wording of phrases. Content validity was confirmed with a few changes considered by experts.

In order to determine the construct validity of the Persian version of the "Palliative Care Attitudes Scale (PCAS-9)" and discover the factors of the scale, the researcher first performed an exploratory factor analysis. Three factors with a specific value greater than 1 were extracted and all items relating to this variable were included in these three factors; this indicates that all three factors in the present study had good internal consistency. Also, according to the factor loads of the items, each of the items had the most factor loads in the same predetermined factor; therefore, the items of the questionnaire had the required validity.

One of the factors extracted was the emotional factor, which is in line with the study of Perry et al. [21]. Moreover, in Milne et al.'s study, the factor of emotional reactions in the Palliative Care Perceptions Questionnaire (PPCl) is consistent with the emotional factor in the present study [34]. The emotional component is the emotional response to a subject. Most research emphasizes the importance of emotional components. In other words, a person's attitude toward a subject cannot be determined simply by identifying his or her beliefs about it, because emotion acts simultaneously with the cognitive process of a subject [35].

Another factor in the present study was the cognitive factor. This factor was also present in the study by Perry et al. [21]. There are also cognitive reactions to palliative care in the study by Milne et al. [34]. The cognitive component is the evaluation of the entity that forms the individual's opinion (belief/disbelief) about the subject. Cognitive dimension refers to the thoughts and beliefs that a person has about a subject [35]. Belief is information that a person has about a subject, information that specifically links a subject and attribute. The cognitive component is the storage section in which the individual organizes the information [36].

Another factor in the present study was the behavioral factor, which is in line with the study by Perry et al. [21]. This factor is consistent with the behavioral factor in the study by Connolly et al. Some of its items include: providing education in palliative care in the context of the local care environment, supporting family members in what to expect where death is imminent, and so on [37]. The behavioral component is a verbal or non-verbal behavioral tendency by an individual and includes observable actions or responses 
that are the result of an attitude issue. This includes the person's response (favorable/unfavorable) to doing something about the subject of the attitude [35].

In confirmatory factor analysis, the results confirm the model fit. In general, the present study showed that the "Palliative Care Attitudes Scale (PCAS-9)" is acceptable for the community of patients in need of palliative care in Iran according to the psychometric results and seems to assess patients' attitudes toward palliative care.

The results showed reliability indicating acceptable stability and internal consistency for this tool. Internal stability (Cronbach's alpha) of factors was more than 0.7 , indicating that it is desirable [34]. In the study by Perry et al., Cronbach's alpha coefficient of the entire English version of the instrument was 0.84 [21]. The results showed that the value of intra-class correlation coefficients (ICC) with $95 \%$ confidence interval for scale factors was an acceptable indicator of the reliability of stability or reproducibility of the questionnaire. Reliability testing is important to determine the accuracy of a questionnaire [38].

One of the limitations of the present study was that due to the fact that this tool was a new tool designed in English and its validation was done in English, so the researcher faced some difficulty and a shortage of resources in obtaining articles in this field and better discussion,.

\section{Conclusion}

The results of the study showed that the Persian version of the tool "Patients' Attitude to Palliative Care Scale (PCAS-9)" was acceptable and sufficient for psychometric results to measure patients' attitudes toward palliative care in Iran. The use of this tool helps to evaluate patients' attitudes toward palliative care and the effectiveness of the training provided to correct negative attitudes toward palliative care.

\section{List Of Abbreviations}

PCAS: Patients 'Attitude to Palliative Care Scale, WHO: World Health Organization, EFA: Exploratory Factor analysis, CFA: Confirmatory Factor Analysis, KMO: Kaiser-Meyer-Olkin, df: degree of freedom, GFI: Goodness of Fit Index, AGFI: Adjusted Goodness of Fit Index, RMR: Root Mean square Residual, NFI: Normed Fit Index, NNFI: Non-Normed Fit Index, IFI: Incremental Fit Index, CFI: Comparative Fit Index, RMSEA: Root Mean Square Error of Approximation, SPSS: Statistical Package for the Social Sciences, LISREL: linear structural relations, SD: standard deviation, $\chi^{2}$ : chi-squared, ICC: intra-class correlation coefficient, PPCl: Palliative Care Perceptions Questionnaire.

\section{Declarations}

\section{Ethics approval and consent to participate:}

In the present study, the general guideline of ethics was used in medical sciences research with human subjects in the Islamic Republic of Iran. This plan was evaluated and approved by the ethics committee 
of Islamic Azad University, Khorasgan Branch, and the ethics code of this plan is IR.IAU.KHUISF.REC.1399.225. All participants first filled out an informed consent form and then entered the study.

\section{Consent for publication:}

“Not applicable”

\section{Availability of data and materials:}

The datasets used and/or analysed during the current study are available from the corresponding author on reasonable request.

\section{Competing interests:}

"The authors declare that they have no competing interests"

\section{Funding:}

The authors received no financial support for the research, authorship, and/or publication of this article.

Authors' contributions:

All authors (SB, MB-SH, KN and MJ-E) have participated in the conception and design of the study. SB contributed the data collection and prepared the first draft of the manuscript. MB-SH and KHN critically revised and checked closely the proposal, the analysis and interpretation of the data and design the article. MB-SH and SB carried out the analysis, interpretation of the data. MJ-E and KN has been involved in revising the manuscript critically. All authors read and approved the final manuscript.

\section{Acknowledgments:}

The authorities, professors and patients participating in this study are hereby thanked and appreciated.

\section{References}

1. Goodarzi M, Ebrahimzadeh I: Impact of Distance Education via short message service of Mobile Phone on metabolic control of Patients with Type 2 Diabetes Mellitus in Karaj-Iran. The Horizon of Medical Sciences 2014, 19(4):224-234.

2. Pefoyo AJK, Bronskill SE, Gruneir A, Calzavara A, Thavorn K, Petrosyan Y, Maxwell CJ, Bai Y, Wodchis WP: The increasing burden and complexity of multimorbidity. BMC public health 2015, 15(1):1-11.

3. Dogru A, Ovayolu N, Ovayolu O: The effect of motivational interview persons with diabetes on selfmanagement and metabolic variables. JPMA 2019, 69(294).

4. Goodman H, Firouzi A, Banya W, Lau-Walker M, Cowie MR: Illness perception, self-care behaviour and quality of life of heart failure patients: a longitudinal questionnaire survey. International Journal of 
Nursing Studies 2013, 50(7):945-953.

5. World Health Organization. Palliative Care. Available from: https://wwwwhoint/healthtopics/palliative-care

6. Gaertner J, Siemens W, Meerpohl JJ, Antes G, Meffert C, Xander C, Stock S, Mueller D, Schwarzer G, Becker G: Effect of specialist palliative care services on quality of life in adults with advanced incurable illness in hospital, hospice, or community settings: systematic review and meta-analysis. bmj 2017, 357.

7. Howie L, Peppercorn J: Early palliative care in cancer treatment: rationale, evidence and clinical implications. Therapeutic Advances in Medical Oncology 2013, 5(6):318-323.

8. Carpenter JG, McDarby M, Smith D, Johnson M, Thorpe J, Ersek M: Associations between timing of palliative care consults and family evaluation of care for veterans who die in a hospice/palliative care unit. Journal of palliative medicine 2017, 20(7):745-751.

9. Hui D, Elsayem A, De La Cruz M, Berger A, Zhukovsky DS, Palla S, Evans A, Fadul N, Palmer JL, Bruera E: Availability and integration of palliative care at US cancer centers. Jama 2010, 303(11):1054-1061.

10. Vallabhajosyula S, Prasad A, Dunlay SM, Murphree Jr DH, Ingram C, Mueller PS, Gersh BJ, Holmes Jr DR, Barsness GW: Utilization of palliative care for cardiogenic shock complicating acute myocardial infarction: a 15-year national perspective on trends, disparities, predictors, and outcomes. Journal of the American Heart Association 2019, 8(15):e011954.

11. Alqahtani F, Balla S, Almustafa A, Sokos G, Alkhouli M: Utilization of palliative care in patients hospitalized with heart failure: A contemporary national perspective. Clin Cardiol 2019, 42(1):136142.

12. Ando T, Akintoye E, Uemura T, Adegbala O, Ashraf S, Pahuja M, Shokr M, Takagi H, Grines CL, Afonso $\mathrm{L}$ : Palliative care referral in ST-segment elevation myocardial infarction complicated with cardiogenic shock in the United States. Heart \& Lung 2020, 49(1):25-29.

13. Chatterjee K, Goyal A, Kakkera K, Harrington S, Corwin HL: National trends (2009-2013) for palliative care utilization for patients receiving prolonged mechanical ventilation. Critical care medicine 2018, 46(8):1230-1237.

14. Graphic PC: Dying in America: Improving quality and honoring individual preferences near the end of life. 2015.

15. Boyd K, Moine S, Murray SA, Bowman D, Brun N: Should palliative care be rebranded? In.: British Medical Journal Publishing Group; 2019.

16. Wang W-L, Herting JR, Tung Y-Y: Adolescents' avoidance of secondhand smoke exposure: model testing. Western Journal of Nursing Research 2008, 30(7):836-851.

17. Moore Z, Price P: Nurses' attitudes, behaviours and perceived barriers towards pressure ulcer prevention. Journal of clinical nursing 2004, 13(8):942-951.

18. Noar SM, Zimmerman RS: Health behavior theory and cumulative knowledge regarding health behaviors: are we moving in the right direction? Health education research 2005, 20(3):275-290. 
19. Conner M, Kirk SF, Cade JE, Barrett JH: Environmental influences: factors influencing a woman's decision to use dietary supplements. The Journal of nutrition 2003, 133(6):1978S-1982S.

20. Ajzen I: The theory of planned behaviour: Reactions and reflections. In.: Taylor \& Francis; 2011.

21. Perry LM, Hoerger M, Malhotra S, Gerhart JI, Mohile S, Duberstein PR: Development and validation of the palliative care attitudes scale (PCAS-9): a measure of patient attitudes toward palliative care. Journal of pain and symptom management 2020, 59(2):293-301. e298.

22. Heydari H: Home-based palliative care: A missing link to patients' care in Iran. Journal of Hayat 2018, 24(2):97-101.

23. Polit DF, Yang F: Measurement and the measurement of change: a primer for the health professions: Wolters Kluwer Philadelphia, PA; 2016.

24. Algoso M, Peters K, Ramjan L, East L: Adaptation and validation of a survey instrument measuring perceived preparedness of nursing graduates. Nurse researcher 2016, 23(6).

25. Wilson HS: Introducing Research in Nursing: Addison Wesley Publishing Company 1987.

26. Younas A, Porr C: A step-by-step approach to developing scales for survey research. Nurse researcher 2021, 29(2).

27. Pett MA, Lackey NR, Sullivan JJ: Making sense of factor analysis: The use of factor analysis for instrument development in health care research: sage; 2003.

28. Munro BH: Statistical methods for health care research, vol. 1: lippincott williams \& wilkins; 2005.

29. Hayton JC, Allen DG, Scarpello V: Factor retention decisions in exploratory factor analysis: A tutorial on parallel analysis. Organizational research methods 2004, 7(2):191-205.

30. TR. L: Confirmatory factor analysis: The International Encyclopedia of Interpersonal Communication; 2015.

31. De Boer MR, Moll AC, De Vet HC, Terwee CB, Völker-Dieben HJ, Van Rens GH: Psychometric properties of vision-related quality of life questionnaires: a systematic review. Ophthalmic and Physiological Optics 2004, 24(4):257-273.

32. Sawatzky R, Porterfield P, Lee J, Dixon D, Lounsbury K, Pesut B, Roberts D, Tayler C, Voth J, Stajduhar $\mathrm{K}$ : Conceptual foundations of a palliative approach: a knowledge synthesis. BMC palliative care 2016, 15(1):1-14.

33. Vinzi VE, Chin WW, Henseler J, Wang H: Handbook of partial least squares, vol. 201: Springer; 2010.

34. Milne D, Aranda S, Jefford M, Schofield P: Development and validation of a measurement tool to assess perceptions of palliative care. Psycho-Oncology 2013, 22(4):940-946.

35. Jain V: 3D model of attitude. International Journal of Advanced Research in Management and Social Sciences 2014, 3(3):1-12.

36. Flanders NA, Fishbein M, Ajzen I: Belief, attitude, intention, and behavior: An introduction to theory and research, vol. 2089: Addison-Wesley; 1975.

37. Connolly M, McLean S, Guerin S, Walsh G, Barrett A, Ryan K: Development and initial psychometric properties of a questionnaire to assess competence in palliative care: palliative care competence 
framework questionnaire. American Journal of Hospice and Palliative Medicine $® 2018,35(10): 1304-$ 1308.

38. Timmins F: Surveys and questionnaires in nursing research. Nursing Standard (2014+) 2015, 29(42):42.

Figures

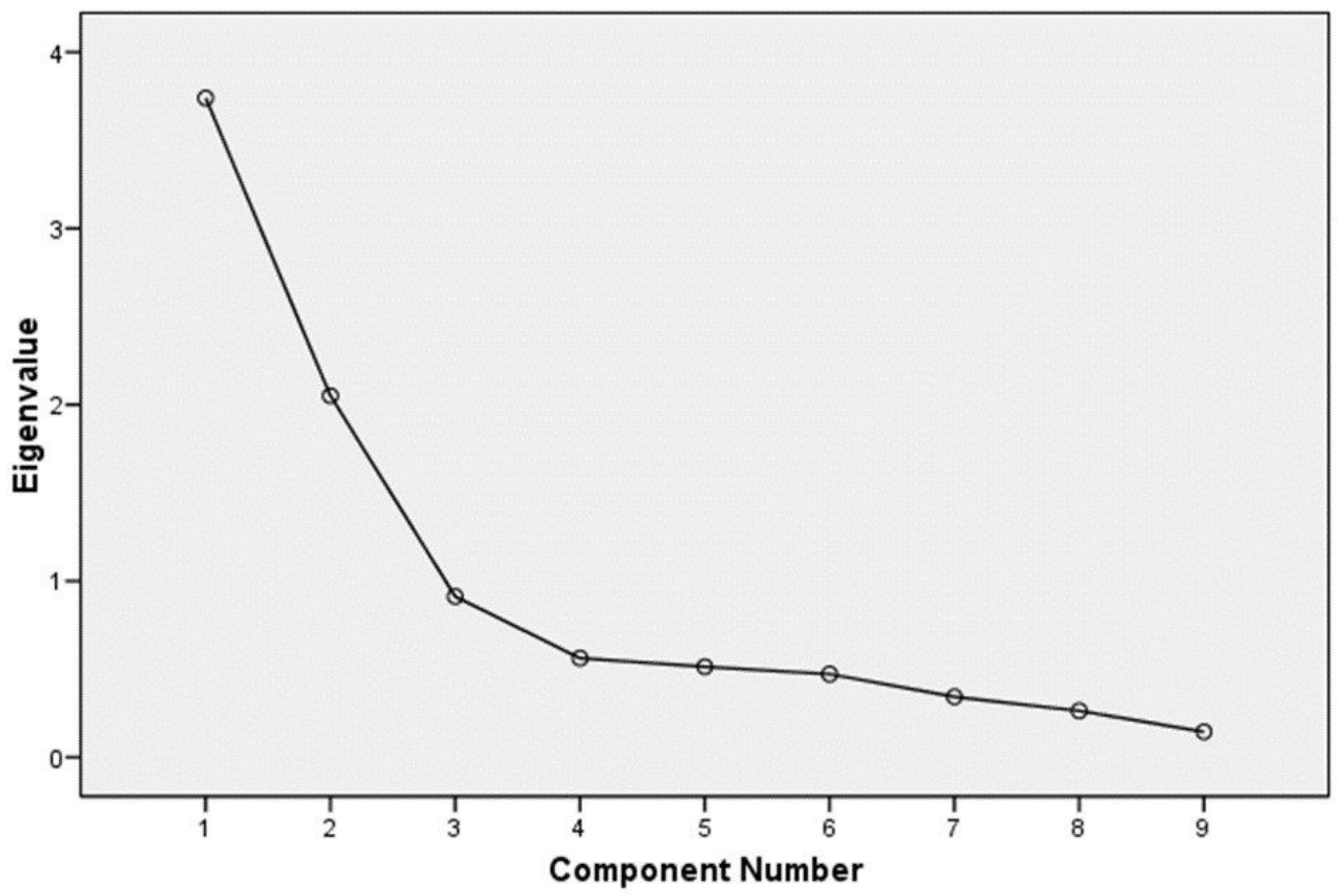

\section{Figure 1}

Gravel diagram to determine the number of appropriate factors to be extracted Palliative care attitudes scale questions 


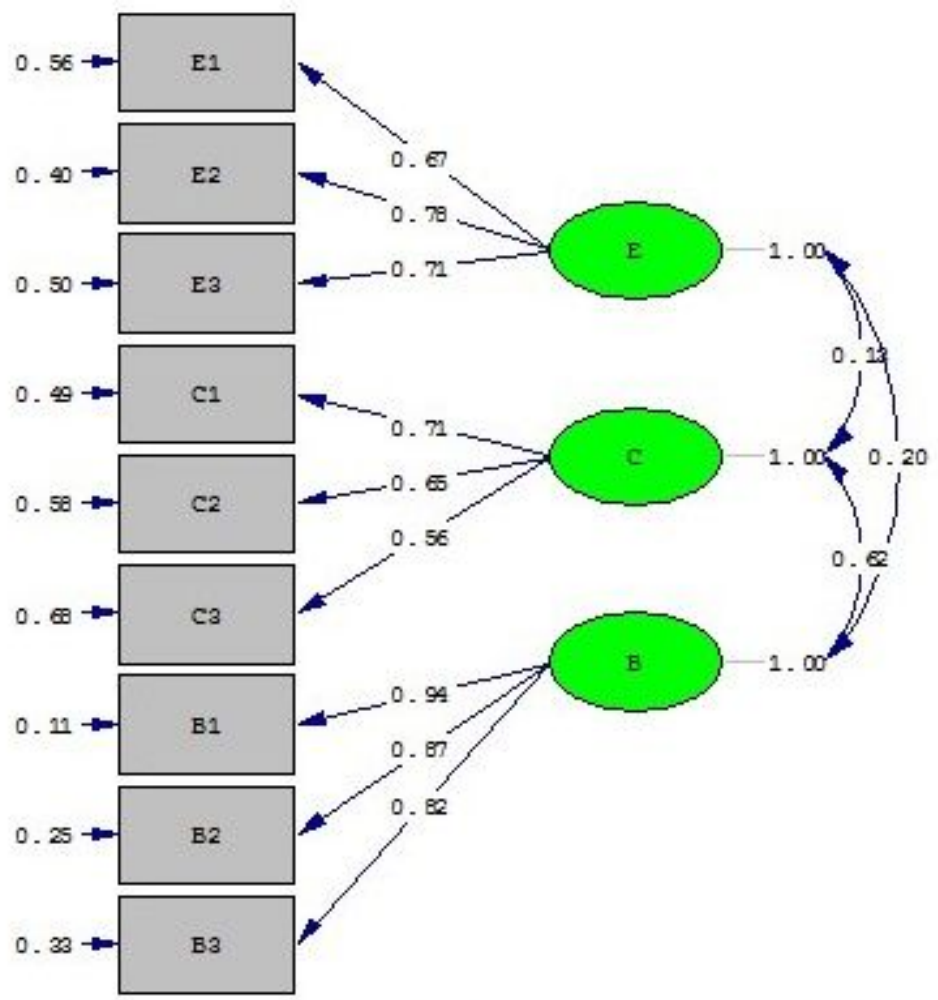

Chi-Square $=20.19, \mathrm{df}=24, \mathrm{P}-\mathrm{value}=0.03573, \mathrm{RMSEA}=0.000$

\section{Figure 2}

Model for measuring the dimensions of palliative care attitudes using factor analysis in standard mode 